\title{
Os escritos de João Rodrigues de Brito (1807): um retrato das novas ideias no mundo ibero-americano
}

\author{
The writings of João Rodrigues de Brito (1807): a picture of the new ideas in the Ibero- \\ American world
}

\author{
Karla Maria Silva \\ Doutora em História \\ Professora do Departamento de História \\ da Universidade Estadual de Maringá \\ silva.karlamaria@gmail.com
}

Resumo: Com o objetivo de contribuir para a reconstituição da história intelectual da formação do Estado Nacional brasileiro, o presente artigo analisa os escritos de João Rodrigues de Brito, elaborados na Bahia em 1807. Expressão das "novas ideias" que emergiam no cenário intelectual do universo ibero-americano em fins do século XVIII e início do XIX, esses escritos revelam a percepção de que os problemas e obstáculos enfrentados pela economia colonial tinham origem na excessiva intervenção do aparelho administrativo português, o que aponta a existência de um importante núcleo intelectual responsável pela propagação de conceitos que serviriam de base à agitação política daquele período.

Palavras-chave: Rodrigues de Brito, Brasil, Novas ideias.
Abstract: In order to contribute to the reconstruction of the intellectual history of the formation of the Brazilian National State, this article analyzes the writings of João Rodrigues de Brito, produced in Bahia in 1807. Expression of "new ideas" that emerged in the intellectual scene of the Ibero-American universe in the late eighteenth and early nineteenth centuries, these writings reveal the realization that the problems and obstacles faced by the colonial economy originated in the excessive intervention of the Portuguese administrative apparatus, which indicates the existence of an important intellectual core responsible for the spread concepts that were the basis for political unrest of that period.

Keywords: Rodrigues de Brito. Brazil. New ideas. 
Ao final do século XVIII e início do XIX, diante das transformações ocorridas tanto no plano das ideias quanto no plano material, o mundo ocidental teve suas estruturas política, econômica e social profundamente abaladas, e protagonizou uma nova fase na história da humanidade. A Revolução Industrial, a emancipação norte-americana, o Iluminismo, a Revolução Francesa, o advento das práticas capitalistas e do ideário liberal, entre outros fatores, alteraram as estruturas mentais da época e desencadearam um questionamento cada vez mais intenso das práticas intervencionistas típicas da era mercantilista.

Nesse contexto, surgiram, em Portugal e no Brasil, grupos de pensadores ilustres e homens públicos que passaram a defender a ideia de que tanto o desenvolvimento da metrópole quanto o da colônia estaria diretamente ligado à maior liberdade nas relações sociais, de produção e comercialização nos dois lados do Atlântico. As renhidas lutas políticas e teóricas acerca da necessidade de liberar ou intervir, travadas além e aquém mar, descortinaram outras possibilidades político-econômicas e apresentaram novos horizontes para um e outro lado.

Este artigo aborda esse ambiente político e intelectual do universo luso-brasileiro no período mencionado, de modo a demonstrar que, naquele início do Oitocentos, medidas liberalizantes de forte impacto para a sociedade colonial eram tema constante nos debates realizados à época e tendência do Estado português. E principalmente, que existia uma articulação entre quadros importantes de Portugal e Brasil no que diz respeito às mudanças do pensamento e das práticas, criando também do lado de cá do Atlântico, uma base intelectual filiada às novas ideias; um grupo organizado antes mesmo de eventos importantes como a abertura dos portos e a revogação das restrições à liberdade de indústrias (1808), com conceitos já formados acerca da sociedade, da economia e da política.

Para tanto, evidenciamos a atuação de importantes personagens ligados ao aparelho administrativo português e analisamos as surpreendentes Cartas econômicopolíticas de João Rodrigues de Brito, um precioso documento do início do XIX que, além de apresentar um exame minucioso da Bahia pouco antes da chegada da Corte ao Brasil, revela a sintonia de agentes coloniais com os novos ventos que movimentavam o mundo ocidental, fornecendo um retrato bastante preciso da base intelectual que daria sustentação ao movimento de Independência deflagrado em 1821, após as deliberações das Cortes de Lisboa. 


\section{A movimentação intelectual e política em Portugal}

Foi principalmente a partir da década de 1790, já sob a batuta de D. João, que a administração portuguesa assumiu uma posição mais flexível, de "abertura", adotando um programa reformista para seus domínios, especialmente o Brasil.

Nesse processo de reorganização do aparelho administrativo português merecem destaque duas emblemáticas figuras designadas por D. João para ocupar cargos estratégicos: Luís Pinto, o Visconde de Balsemão, e D. Rodrigo de Souza Coutinho, o Conde de Linhares, os quais representam o espírito de renovação que se colocava à época; esses homens ocuparam ministérios e secretarias importantes durante uma fase crucial para os destinos de Portugal e sua principal colônia, e influenciaram diretamente as decisões relativas aos domínios ultramarinos portugueses.

O primeiro cargo de destaque ocupado por Luís Pinto de Souza Coutinho foi o de Governador de Mato Grosso (1769-1772), o que lhe conferiu profundos conhecimentos no que diz respeito ao Brasil. Foi ministro de 1788 a 1801 e Secretário de Estado dos Negócios Estrangeiros e da Guerra, no mesmo período. Além disso, no ano de 1796 assumiu interinamente o Ministério dos Domínios Ultramarinos. O início da circular que ele escreveu aos governadores logo após assumir esse ministério deixa transparecer não só sua percepção dos problemas, mas também o espírito da época: “Devendo persuadirse, que alguns defeitos políticos, e restrições fiscais, se tem oposto até agora aos seus progressos [do Brasil]”... (COUTINHO, 1796 apud MAXWELL, 2001: 233)

Convencido de que era necessário promover mudanças, Luís Pinto esboçou importantes propostas de reformas, entre elas a abolição do monopólio do sal e da pesca da baleia no Brasil, e a instalação da manufatura do ferro. Para formular com precisão e implantar tais reformas, indicou D. Rodrigo de Souza Coutinho, seu interlocutor e amigo, para ocupar seu lugar no Ministério. Consta que Luís Pinto teria sido responsável por enviar à Europa, no ano de 1790, dois jovens estudantes brasileiros que, mais tarde, tornar-se-iam personagens de grande destaque no cenário brasileiro: José Bonifácio de Andrada e Silva, e Manoel Ferreira da Câmara, o futuro Intendente Câmara, protagonista da conhecida obra de Marcos Carneiro Mendonça (1958), e de quem trataremos adiante.

Quanto a D. Rodrigo, cujo padrinho de batismo foi Sebastião José de Carvalho e Melo, o Marquês de Pombal, teve uma sólida formação intelectual no espírito da Ilustração; desde tenra idade frequentou os mais altos círculos do poder em Lisboa e em 
Madri, onde seu pai foi embaixador. De acordo com Andrée Mansuy Diniz Silva, que dirigiu e escreveu a Introdução da obra D. Rodrigo de Souza Coutinho: textos políticos, econômicos e financeiros (1783-1811), na mesma época o tio de D. Rodrigo foi embaixador na França, o que lhe deu a oportunidade de conhecer a sociedade francesa e de entrar em contato com os intelectuais mais brilhantes da época, como d'Alembert, Laplace, Abade Raynal, entre outros.

Em plena “viradeira”, após o fim do reinado de D. José I, D. Rodrigo foi nomeado ministro plenipotenciário de Portugal no então Reino da Sardenha, cuja capital era sediada em Turim, onde exerceu a função no período de 1779 a 1796. Deixou o cargo para ser Ministro e Secretário de Estado da Marinha e Domínios Ultramarinos entre 1796 e 1801, ano em que, sucedendo a Luís Pinto por alguns meses, ocupou interinamente a cadeira de Primeiro Ministro de Portugal. Na sequência foi Presidente do Real Erário e Ministro e Secretário de Estado da Fazenda (1801-1803), e Ministro da Guerra e Negócios Estrangeiros (1808-1812).

Entre seus comentadores, D. Rodrigo é sempre descrito como um homem das "luzes" e apresentado como um administrador otimista e determinado, que planejava profundas reformas e pretendia basear suas medidas em princípios liberais. A já citada Andrée Mansuy Diniz Silva apontou D. Rodrigo como um intelectual em sintonia com as mudanças de seu tempo, que

insere-se assim numa linhagem de personalidades portuguesas do iluminismo crítico do século XVIII português e europeu, que, tendo vivido um longo período no estrangeiro em contato com movimentos políticos e intelectuais de grande amplitude, se distinguiram pela formação científica, pela cultura, pelo cosmopolitismo, e pela ambição de participar na grande transformação que visionavam para o seu país (SILVA, 1993: 39).

Em outra passagem da mesma Introdução, a autora complementa o perfil de D. Rodrigo e evidencia sua proximidade com o emergente pensamento liberal, classificandoo como um autêntico discípulo de Smith,

cujas teorias perpassam em muitos dos seus escritos, e em cuja lição nunca deixou de meditar; [...] No período que vai da queda de Pombal em 1777 à Revolução Liberal de 1820, D. Rodrigo de Souza Coutinho foi o homem de Estado e o político das Luzes que mais convictamente conduziu na via das 
grandes reformas administrativas e financeiras, e orientou a sua ação governativa no sentido da mudança das mentalidades e da reforma das instituições, preparando assim a sociedade portuguesa e brasileira para a eclosão do liberalismo (SILVA, 1993: 51/52).

Lembremos que tal como Luís Pinto e D. Rodrigo, outras figuras com papel ativo no aparelho administrativo português também defenderam ideias liberalizantes e contribuíram para a implantação de muitas reformas. Uma das mais significativas reformas empreendidas por esse grupo foi a abolição do estanco do sal, ensaiada por Luís Pinto em 1797, mas somente efetivada em 1801, sob os auspícios de D. Rodrigo.

O monopólio do sal - gênero cuja escassez foi motivo de inúmeras tensões durante todo o período colonial, como revelou o clássico estudo de Myriam Ellis (1955) - foi abolido pelo Alvará de 24/04/1801, o mesmo que também aboliu o monopólio da pesca da baleia, suspendeu os direitos reais sobre o ferro e estimulou sua extração, comercialização e manufatura, e ainda autorizou a instalação da fábrica real de pólvora.

Com efeito, embora as medidas reformistas de Portugal tenham ficado bastante evidentes no mencionado Alvará de 1801, é importante destacar que elas já eram tendência um pouco antes, e que, para serem implantadas contaram também com o auxílio dos governadores das capitanias, que pressionados pela administração metropolitana, governavam no sentido de aplicar e desenvolver a política proposta. Inúmeras ordens, determinações, alvarás, instruções e outros documentos de natureza diversa revelam o movimento da administração portuguesa no sentido de reformar a política econômica referente ao Brasil.

Bom exemplo disso é a Instrução enviada por D. Rodrigo a D. Fernando José de Portugal, então governador da Bahia, em 1798. Havia chegado à Coroa a notícia de que em algumas capitanias do Brasil, principalmente no interior, se praticavam "algumas vexações que oprimem os cultivadores das terras, e desanimam a agricultura", e Sua Majestade, através de D. Rodrigo, mandava que o governador tomasse providências. Na Instrução ficam claras as concepções de D. Rodrigo, que chamou a atenção para os obstáculos criados ao livre comércio, pois entendia como danosas

as proibições que muitas vezes fazem as Câmaras para a saída dos gêneros para fora, com o pretexto de que se não venha a experimentar falta na terra, sendo indubitável que tais proibições (que só se devem permitir em caso de extrema necessidade) produzem ordinariamente todo o mal, sem fazerem bem 
algum; quando pelo contrário a inteira e livre circulação de todos os gêneros, e a segurança de um mercado, onde os preços só dependem da concorrência, são os melhores meios de procurar uma segunda abundância. Estes são os princípios inalteráveis que S. M. manda lembrar a V. S. para que sirvam de regra nas ocasiões correntes (COUTINHO, 1999: 93).

A partir da análise de documentos como o do exemplo acima é possível afirmar que, na passagem do século XVIII para o XIX, os homens que comandaram a política econômica de Portugal, inclusive no que diz respeito ao Brasil, foram envolvidos pelas novas tendências da época. Superando a ideia de que as medidas adotadas por esses quadros da administração portuguesa foram efetivadas com o intuito de contornar possíveis tensões com a colônia e prevenir uma iminente revolução, poderíamos compreendê-las como expressão da tentativa de integrar o desenvolvimento colonial e o metropolitano, sob a influência do espírito de renovação derivado do pensamento ilustrado e dos princípios liberais.

Cabe lembrar que para alguns historiadores essa tendência não seria expressão da adesão às "novas ideias", disseminadas principalmente a partir dos escritos de Smith; para parte da historiografia essa tendência se encaixa nos quadros gerais do reformismo ilustrado do mundo ibérico, e pode ser entendida como uma espécie de continuidade da ação política do Marquês de Pombal.

Esse é, por exemplo, o entendimento de Fernando A. Novais; em Portugal e Brasil na Crise do Antigo Sistema Colonial (1777-1808), ele acentuou sobremaneira a continuidade da política econômica pombalina e afirmou que "o fomento posto em andamento pelo ministro de D. José" foi significativo e "teve persistência e desdobramentos" para além de sua administração, "prosseguindo em atuação" (NOVAIS, 1989: 132). Essa ideia aparece também no trabalho em que, em parceria com José Jobson de Arruda, discute o papel de Cairu como estadista; a linha de raciocínio é a mesma, e "a mobilização do espírito crítico em Portugal, com a finalidade de viabilizar as reformas necessárias para o Império" é apontada como própria do "movimento mais geral da ilustração", iniciado em Portugal com Pombal (NOVAIS \& ARRUDA, 2003: 232).

José Luís Cardoso e Alexandre Mendes Cunha (2011), em trabalho que mapearam as influências na concepção e execução das reformas empreendidas pelo Estado português no período, identificaram "importantes traços de continuidade entre os 
governos de Pombal e D. Rodrigo, respondendo ambos, ainda com especificidades bem marcadas, ao rótulo geral de reformismo ilustrado" (CARDOSO \& CUNHA, 2011: 68).

Partindo da premissa de que o reformismo ilustrado pode ser identificado como um instrumento de adaptação e não de transformação, essa historiografia aponta a existência de uma separação entre as formulações econômicas e políticas por parte dos homens que encabeçaram as reformas. A grande preocupação era com "a necessidade de aumentar as receitas do Estado, o aumento da produção de mercadorias coloniais para reexportação, a expansão da estrutura de manufaturas na metrópole e a redução do contrabando no comércio colonial" (CARDOSO \& CUNHA, 2011: 82).

Assim, o foco seria a prosperidade comercial do império português. Ainda de acordo com essa vertente historiográfica, do ponto de vista político preocupava os efeitos que os discursos de corte liberal poderiam trazer para a colônia, uma vez que o Império era considerado uno e indivisível. Segundo Jancsón e Pimenta (2000: 145), o próprio D. Rodrigo, "expoente maior" da elite política reformista, comungava dessa concepção.

Independente da concepção que deu origem às reformas, a partir de 1808, quando, em razão das guerras napoleônicas a Corte portuguesa se transferiu para o Brasil e se instalou no Rio de Janeiro, as medidas reformistas empregadas pelo aparelho administrativo português se intensificaram e se tornaram ainda mais evidentes, como a abertura dos portos (1808), que autorizava o comércio com as nações amigas de Portugal, marcando assim o fim das restrições ao comércio colonial. A partir de então, a tendência foi o esgarçamento dos monopólios e o aumento das atividades mercantis.

Desse modo, podemos dizer que os atos que indicam uma ruptura com "as antigas práticas mercantilistas, não caíram como um dia ensolarado" e que "a liberalização econômica de 1808 já estava sendo preparada no campo das ideias"... (PEREIRA.; PEREIRA \& SILVA, 2009: 69).

\section{As novas ideias no Brasil: as Cartas econômico-políticas de Rodrigues de}

\section{Brito}

A essa conjuntura reformista vivida pelo mundo luso-brasileiro estavam vinculados inúmeros pensadores e agentes administrativos importantes da colônia, como Azeredo Coutinho, José da Silva Lisboa (futuro Visconde de Cairu), Dom Fernando José de Portugal (Marquês de Aguiar, governador da Bahia de 1788 a 1801), João Saldanha 
da Gama de Mello e Torres ( $6^{\circ}$ Conde da Ponte, governador da Bahia de 1805 a 1810), e Marcos de Noronha e Brito (Conde dos Arcos - governador da Bahia de 1810 a 1818), bem como funcionários de menor escalão, como Manoel Ferreira da Câmara. A esse "grupo de administradores e intelectuais dinâmicos" - expressão utilizada por Stuart B. Schwartz em Segredos Internos (1999) para se referir ao conjunto dos homens públicos guiados pelas novas ideias - pertencia também João Rodrigues de Brito, juiz da Relação da Bahia, conhecido por apreciar os princípios econômicos defendidos por Adam Smith.

Os escritos do desembargador Brito expressam bem as ideias dessa elite intelectual que olhava a economia e a sociedade colonial sob a perspectiva inovadora da Economia Política e das recentes possibilidades abertas ao mundo luso-brasileiro pelo novo contexto internacional daquela agitada virada de século. Suas ideias podem ser observadas em Cartas econômico-políticas sobre a agricultura e comércio da Bahia (1807), documento revelador que esclarece pontos importantes da realidade baiana do início do século XIX; trata-se de escritos de vários autores, publicados sob a forma de livro em 1821, em Lisboa, e reeditados em Salvador em 1923, pela Livraria Progresso Editora, com o título A Economia Brasileira no Alvorecer do Século XIX, sob o influxo da comemoração do centenário da Independência política do Brasil.

Os textos que compõem essa obra originaram-se de um inquérito mandado realizar pelo então Governador da Capitânia da Bahia, Conde da Ponte, a pedido do Príncipe Regente Dom João. Segundo I. A. F. Benevides, editor da edição de 1821, o inquérito teria sido motivado por queixas de moradores da Bahia (principalmente contra supostos excessos cometidos pela Mesa de Inspeção) apresentadas ao Príncipe Regente. Tal como ordenara o Regente do trono, o Conde da Ponte encarregou o Senado da Câmara de Salvador de realizar um inquérito para apurar a procedência ou não das queixas, bem como para obter sugestões que pudessem impulsionar a economia colonial. O Senado da Câmara, por sua vez, deliberou socorrer-se das "luzes e talentos" dos principais lavradores, comerciantes e letrados daquela capitania, como consta no Ofício enviado pelos vereadores às personalidades solicitadas a colaborar na consulta.

Segundo o Ofício do Governador Conde da Ponte, transcrito pelo editor lisboeta e mantido na edição brasileira de 1923, os consultados deveriam responder a 5 quesitos: $1^{\circ}$ ) se existia na Bahia alguma causa opressiva à lavoura, qual esta causa e o meio de evitá-la; $2^{\circ}$ ) se a lavoura recebia "progressivo aumento", e qual o motivo favorável ou não a este respeito; $3^{\circ}$ ) se o comércio da capital sofria "algum vexame" e, em caso positivo, qual era e o que fazer para "desoprimi-lo dele sem risco de outro maior dano"; 
$4^{\circ}$ ) se os diferentes exames sobre a boa qualidade dos gêneros de exportação da colônia, e "mais cautelas que se praticam a respeito dos mesmos gêneros", eram úteis ou "nocivas ao progresso do comércio"; $5^{\circ}$ ) se o lavrador desobrigado de tais exames e o comerciante livre para "convencionar-se nos preços dos gêneros", não promoveriam melhor seus interesses.

Entre as autoridades e personalidades consultadas pela câmara de Salvador encontrava-se o desembargador João Rodrigues de Brito, conceituado jurista que mais tarde atuaria também na Relação de São Luiz do Maranhão e depois junto às Cortes de Lisboa, onde ocuparia a cadeira de Deputado representando a Província do Alentejo. Além de Rodrigues de Brito, cuja resposta é um trabalho de fôlego, também foram indicados para responder ao inquérito o já citado Manoel Ferreira da Câmara, José Diogo Ferraz de Castelo Branco e Joaquim Inácio de Sequeira Bulcão. De todas as respostas, a de Brito - que analisamos mais adiante - é a mais interessante, seguida pela de Câmara. Os outros consultados apresentaram respostas curtas e burocráticas.

Antes de comentarmos as respostas obtidas, devemos chamar a atenção para o fato incontestável de que a realização do inquérito, por si só, revela a efetivação dos planos de reforma empreendidos, principalmente, pelo futuro Conde de Linhares, que à época era membro do Conselho de Estado português (1804-1807). Como é possível verificar parágrafos acima, os quesitos sobre os quais os inquiridos deveriam refletir são a mais pura expressão do novo pensamento em voga, que, entre outras coisas, via na liberdade da produção e do comércio o caminho mais rápido e eficaz para o progresso e o desenvolvimento; a título de exemplo, citemos o $5^{\circ}$ quesito: somente uma administração ancorada nas "novas ideias" poderia levantar a hipótese de que deixar os lavradores e os comerciantes da colônia mais livres para desenvolver suas atividades atenderia melhor aos seus interesses.

Passemos às respostas do inquérito. A de Manoel Ferreira da Câmara - importante cientista e intelectual mineiro, membro da Real Academia de Ciências de Lisboa, que transitou entre a elite culta de Portugal e ocupou diversos cargos públicos na administração portuguesa - é considerada, ao lado da Brito, um precioso testemunho das dificuldades pelas quais passavam não só os produtores e comerciantes da cidade de Salvador, mas provavelmente os de toda a América portuguesa. Em um pequeno trecho de sua carta-resposta, podemos verificar um pouco de suas concepções e claramente perceber uma postura crítica em relação aos excessivos regulamentos impostos aos produtores e comerciantes de Salvador. Em um dos trechos, Câmara afirma que, quanto 
mais um gênero é necessário, "menos o governo se deve embaraçar da sua produção, seja agriconômica (sic), seja mercantil; e direi ainda mais, menos convém que ele faça Regimentos, ou tome medidas para que ele se venda por menos do que realmente se custa fabricar, e a transportar, quero dizer, abaixo do seu preço natural (FERREIRA DA CÂMARA, IN: BRITO, 1923: 155).

Numa outra passagem, ele é ainda mais enfático no que diz respeito à defesa de liberdade dos produtores e deixa evidente sua adesão aos princípios do livre-câmbio ao declarar que:

Já VV. SS. preverão que eu não entendo que se faça bem a alguém, obrigandoo; e que duvido muito que por esse meio se consiga algum dia o que se pretender. Cada um deve ser senhor de fazer o que mais lhe convier; e o que mais lhe convier é o que mais convém ao Estado, e ao Soberano, que tem partilha em todos os seus lucros, e interesses (FERREIRA DA CÂMARA, In: BRITO, 1923: 165).

Quanto a João Rodrigues de Brito - a quem o editor lisboeta das Cartas... atribui a ideia de criação da cadeira de Economia Política do Rio de Janeiro, a qual deveria ser ocupada por Cairu em 1808 - sua resposta foi mais profunda e complexa; ele tratou não apenas de questões que faziam referência aos aspectos econômicos indicados pelo inquérito, mas também daquelas relacionadas à organização política, social e cultural da Bahia e da colônia de forma geral ${ }^{1}$. Essa resposta merece ser esmiuçada.

Entre outros assuntos, o desembargador tratou do que hoje chamamos de relações de gênero. Ele criticou o antigo costume de reclusão doméstica das mulheres, lamentando o desperdício de braços em que isso implicava. Antenado ao que se passava no mundo, como na Inglaterra, por exemplo, nesse ponto Brito (1923: 100) elogiou as "nações mais civilizadas da Europa, onde o belo sexo se ocupa em vender nas lojas, e no exercício de todas as artes, que não exigem grandes forças"; afirmou que introduzir esse costume no Brasil, além de proporcionar a independência feminina, "duplicaria a soma das riquezas anualmente produzidas pelo trabalho humano", e ainda, que "o hábito do trabalho ativo lhes daria uma constituição física mais vigorosa e animada", pois lamentava ver "a maior parte das senhoras definhar em moléstias nervosas, precedidas da inação, e enjôo, em que vivem".

\footnotetext{
${ }^{1}$ Para um estudo aprofundado de Rodrigues de Brito ver SILVA, 2007.
} 
Também foram alvo das críticas de Brito os votos monásticos, pois fomentavam a "ociosidade e a despovoação", dois grandes obstáculos ao desenvolvimento da sociedade colonial. Para o autor (1923: 95), o voto de castidade "é contrário à propagação, e ainda mais à procriação da prole"; o de pobreza "contrário à riqueza" e com um agravante: "prometer ser pobre é dizer que ser sustentado pelo trabalho de outros, como zangões nas colmeias"; o de obediência "é diretamente contrário aos princípios do Direito público, e ordem social, que só prescreve a obediência dos Cidadãos à Lei”; e o de clausura "diretamente contrário à sociedade, e liberdade".

Figurou ainda nas observações de Brito o descaso do poder público com o bom funcionamento da sociedade, já que deixava de cumprir funções essenciais como cuidar das vias de acesso, por exemplo, pois para ele (1923: 82) “a primeira [facilidade], com que o Governo de qualquer país a deve favorecer é a construção, e conservação das pontes, e barcas para a passagem dos rios, estradas, canais, estivas”. Segundo Brito, tal realidade seria expressão das limitações culturais da própria população, não excetuando a chamada elite colonial. Ele queixou-se, também, da atitude de indiferença dos habitantes de Salvador e de sua desatenção ao que é essencial; escreveu Brito (1923: 124) que a população da capital baiana gastava espontaneamente "mais de meio milhão por ano em funerais, e festas de Igreja, e nem um vintém em caminhos, cais, fontes, pontes e obras úteis". Ou seja, tratava-se, segundo ele, de um grave problema cultural que só poderia ser resolvido com a reeducação do povo. Nesse sentido, sugeriu:

Se em vez de lerem vidas de Santos cheias de piedosas fraudes, lessem livros desta Ciência sublime [Economia Política], suas despesas se encaminhariam como na Grã Bretanha, para dockes e outras obras patrióticas. (...) Ainda não se viu um Economista que fosse um mau cidadão, diz o grande Say no Prefácio do seu insigne tratado. E esta consideração, ainda não desmentida, justifica ao célebre Dupont de Nemours, que primeiro entre os todos os Economistas demonstrou que este estudo pertencia a todas as classes de Cidadãos, sem excetuar o belo sexo... (BRITO, 1923: 125).

Essas e outras colocações de Rodrigues de Brito denotam sua vinculação ao pensamento reformista, que ganhava adeptos não apenas em Portugal, mas também no Brasil.

Vejamos o que escreveu Brito em relação aos problemas econômicos. A reflexão sobre o primeiro quesito do inquérito - se exista naquela cidade "alguma causa opressiva 
contra a lavoura; qual seja esta causa, e o meio dela se evitar" - foi a parte mais longa de seu texto. Sua argumentação foi dividida em três partes distintas que representavam, em sua opinião, as três classes dos principais problemas: a primeira classe constituía na falta de liberdade dos lavradores; a segunda, na falta de facilidades para auxiliar a liberdade; a terceira classe, nas dificuldades que a falta de instrução causava aos lavradores.

A primeira crítica de Brito diz respeito à determinação que obrigava os lavradores a plantar quinhentas covas de mandioca para cada escravo de serviço ${ }^{2}$. Algo semelhante pesava sobre os "negociantes de escravatura", que estavam obrigados a cultivar quanta mandioca fosse necessária para abastecer os seus navios. $\mathrm{O}$ autor reconhecia a nobreza dos objetivos de tais imposições, pois visavam evitar a carestia da farinha de mandioca e garantir a regularidade do abastecimento daquele "gênero de primeira necessidade". Contudo, segundo o mesmo autor, tal imposição teve efeito oposto. Ele dizia não duvidar da pureza das intenções de tais determinações, mas acreditava que elas não bastavam para alcançar o bem público e que aquelas leis eram "diretamente contrárias ao Comércio das farinhas, prejudicam igualmente à Lavoura da cana, e à das farinhas sem proveito do Comércio da escravatura" (BRITO, 1923: 54).

No entendimento do desembargador (1923: 54), o plantador de cana era obrigado a ocupar "com a mesquinha plantação de mandioca", que pode ser cultivada em terras de menor fertilidade, "os raros e preciosos torrões de massapé, aos quais a natureza deu o privilégio de produzirem muito bom açúcar, e outros gêneros de grande valor". O produtor de farinha, por sua vez, seria prejudicado porque a lei forçando os lavradores de “açúcar, tabaco e outros cidadãos a cultivar per si mais do que podem gastar em suas casas, já os próprios lavradores delas não acham tão fácil saída às das suas lavras", sem que pudessem dar às suas terras outro destino, "por não serem capazes de produzir açúcar, algodão, café, etc.” (1923: 54/55). Para Brito, a excessiva intervenção do Estado estaria na raiz da carestia nos centros urbanos, fenômeno tão comum no Brasil colonial. Com a diminuição da produção, não só o lavrador era prejudicado, mas também o Estado, pois perdia na arrecadação de impostos, além de eventualmente ter de enfrentar sublevações da plebe urbana em função das crises de abastecimento e consequente elevação de preços dos gêneros de primeira necessidade.

\footnotetext{
2 Alvará de 25/01/1688, com disposições renovadas pelo Alvará de 27/01/1701 e pela Provisão de 28/04/1767, ainda vigente quando Brito respondeu ao inquérito.
} 
Sobre a imposição do cultivo da mandioca pelos negociantes da escravatura, Brito (1923: 55) também as julgava inconvenientes e de difícil cumprimento, pois os armadores de navios negreiros preferiam "antes comprar a farinha pelo preço corrente no mercado, do que distraírem-se com a cultura dela". No entendimento do autor (note-se, muito semelhante ao de Ferreira da Câmara), os cidadãos não deveriam estar expostos a imposições relacionadas ao emprego de seus braços e capitais; é o cidadão e não o Estado quem sabe como melhor aplicar seus recursos, pois ele mesmo é o maior interessado. $\mathrm{O}$ lavrador sofreria duplo prejuízo, "pois tanto sofre o Lavrador em ser obrigado a cultivar um gênero que lhe rende menos, como deixa de cultivar outro, que lhe renderia mais" (1923: 55). Brito criticou veementemente a intervenção do Estado sobre a produção e afirmou que

Em geral todas as vezes que a Administração pública se intromete a prescrever aos cidadãos o emprego, que eles hão de fazer de suas terras, braços e capitais, ela desarranja o equilíbrio, e natural distribuição daqueles agentes da produção das riquezas, cujo uso ninguém pode melhor dirigir que o próprio dono, que é nisso o mais interessado, e que por essa razão faz deles o objeto das suas meditações (BRITO, 1923: 55/56).

Observe-se que, ao fazer tais colocações, Brito apoia-se expressamente nos princípios da divisão do trabalho desenvolvidos por Smith, demonstrando estar em sintonia com as mais recentes teorias econômicas de seu tempo. Com efeito, em $A$ Riqueza das Nações (1996), Smith defendeu a ideia de que a divisão social do trabalho é uma condição essencial ao desenvolvimento da sociedade. Para o economista escocês, o aperfeiçoamento da produção e o aumento da produtividade seriam diretamente proporcionais ao grau de divisão do trabalho existente numa sociedade.

Nesse sentido, as colocações do desembargador Brito alinham-se às de Smith; assim como o pensador escocês, Brito acreditava que se cada produtor se dedicasse apenas a uma única atividade, a produção seria maior e melhor, o que consequentemente acarretaria numa oferta também maior e melhor desse produto, evitando assim a escassez e a carestia do mesmo. Mas a principal consequência dessa imposição seria, no entendimento de Brito, o retardamento da formação de uma economia de mercado na colônia. Caso aqueles alvarás fossem cumpridos à risca, o seu efeito prático seria tornar 
autárquicas as unidades produtivas da colônia. Com isso, nunca se criaria um mercado de farinhas nem de qualquer outra coisa.

Brito também teceu duras criticas à falta de liberdade dos lavradores em criar em suas propriedades estruturas como alambiques e engenhos sem prévia licença de inspetores, a qual somente era concedida após o cumprimento de "certos requisitos e formalidades dispendiosas"; para conseguir a licença obrigatória, os lavradores tinham de enfrentar muita burocracia e morosidade, e ainda adular os responsáveis pelas liberações (BRITO, 1923: 57).

Essa condição favorecia alguns senhores de engenho que já possuíam tais estruturas, pois aqueles que estavam impedidos de providenciá-las eram obrigados a moer suas canas em engenhos determinados, agravando o problema dos monopólios. Os donos de engenho não viam com bons olhos as novas edificações e desejavam afastar "a concorrência dos que lhe vem diminuir suas vantagens". Contrariando essa concepção e comungando dos princípios livre-cambistas, Brito (1923: 58) apreciava a concorrência, para ele "o gérmen fecundo da emulação, sem a qual se não deve esperar melhoramento de ramo algum da indústria humana".

Além desses inconvenientes, o desembargador (1923: 83) ainda fez constar que os produtores coloniais sofriam constantemente com a generalizada ausência de infraestrutura que, na melhor das hipóteses, fazia com que boa parte de sua produção se perdesse. Com a falta de pontes, estradas e demais facilidades para se transportar os gêneros a serem comercializados, os produtores ficavam à mercê dos fenômenos naturais, pois estes eram o fator determinante das condições em que se encontravam as vias de transporte. Se por ventura viesse a chover intensamente, principalmente em regiões baixas, o produtor, para evitar a perda de animais além de parte de seus gêneros, via-se obrigado a "empatar sua safra até o verão seguinte".

A precariedade dos meios de transporte não era um problema exclusivo das áreas mais remotas da Capitania. Segundo ele, nas próprias vizinhanças de Salvador as estradas eram íngremes e impraticáveis para os carros, fazendo-se o transporte "às costas de escravos muito mais dispendiosamente". Brito mostrou-se indignado com a realidade dos arredores de Salvador: “Que lástima! Que vergonha! Aqui mesmo nas vizinhanças desta populosa Cidade! não só o Governo falta ao dever de estabelecer barcas, ou pontes, mas opõe obstáculos ao seu estabelecimento" (BRITO, 1023: 83).

Assim, uma questão importante a ressaltar é que Rodrigues de Brito não era totalmente contrário à intervenção do Estado sobre a produção. Ele aponta para diversas 
situações em que o Estado deveria intervir; em sua concepção, propiciar aos produtores o mínimo de infraestrutura, como a construção de pontes e providenciar a disponibilidade de barcas, por exemplo, seria uma forma eficaz de intervenção, e evitaria ainda o tão criticado descaso do poder público, mencionado há pouco.

Contudo, os obstáculos a serem encarados pelos lavradores da Capitania da Bahia não se resumiam às questões já analisadas. Existia outro problema bastante complexo: o excesso dos monopólios. Para Rodrigues de Brito praticamente todos os males que impediam o desenvolvimento da colônia tinham uma única origem, qual seja a política mercantilista e sua tradição de intervencionismo estatal.

Cercados de leis e restrições por todos os lados, os lavradores se encontravam limitados e não tinham nem mesmo o direito de comercializar livremente os gêneros por eles produzidos. Depois de terem de cultivar somente os gêneros permitidos e de enfrentar os inconvenientes de seu beneficiamento, não poderiam vender livremente sua produção, pois pesava sobre esta, inúmeras formalidades e encargos. Segundo Brito, tal situação não propiciava condições para que a sociedade prosperasse. De acordo com os princípios do livre-câmbio - os quais Brito demonstrou admirar em diversas passagens de seus escritos - na busca de seus próprios interesses, cada indivíduo serviria melhor aos interesses da sociedade. Nesse sentido, como os indivíduos poderiam servir aos interesses da sociedade, e consequentemente aos do Estado, se seus próprios interesses eram tolhidos? De acordo com o desembargador, "esta privação tem infalíveis, e fatais consequências contra a Lavoura; porque o lavrador não fez nascer aqueles frutos senão pela esperança de próprio interesse: é lei universal da natureza, que se não pode violar impunemente" (BRITO, 1923: 58).

Para exemplificar o problema do excesso de leis e restrições, convém citar o caso dos produtores de farinha, grãos e legumes, que tinham que encaminhar sua produção para os celeiros públicos predeterminados; sofriam assim as despesas de uma viagem desnecessária, o empate do seu capital e ainda a desvalorização e até deterioração de sua mercadoria que, não raras vezes, permanecia nos celeiros por mais de um mês. Mesmo que o comprador fosse vizinho seu, o produtor não poderia vender seu gênero, pois não lhe era permitido comercializar sem autorização (BRITO, 1923: 60).

Assim, além dos males causados à esfera da produção, o intervencionismo do poder público interferia também de forma nociva na comercialização da farinha e de outros gêneros nos centros urbanos; como é possível perceber, os lavradores não tinham a liberdade de escolher quando, onde ou para quem considerassem mais conveniente 
vender sua produção. Brito era terminantemente contra essas proibições e acreditava que tanto o produtor quanto o consumidor são prejudicados com essas práticas, pois, segundo ele,

Quando aquele prefere antes vendê-los [seus frutos] por junto no caminho, ou já no porto, é porque acha nisso o seu interesse. É porque lhe convém mais aproveitar o tempo, voltando prontamente à sua lavoura... E este interesse do Lavrador é o interesse geral mesmo dos consumidores das Cidades; porque a maior produção, que resulta deles assistirem nas suas terras, e das vendas favoráveis, difunde a abundância por toda a parte, e com esta o bom preço, que não pode vir constantemente senão dela (BRITO, 1923: 75).

O desembargador comentou ainda o exagero de restrições e regulamentos relacionados ao comércio do tabaco, gênero cuja exportação para a Europa causava inúmeros constrangimentos e prejuízos aos seus produtores:

Os tabacos, pela Provisão de 27 de outubro de 1785, e outras ordens posteriores, não podem sair dos portos do Recôncavo, senão passado dia 20 de janeiro, por se entender que antes não poderiam estar devidamente beneficiados [...] Sei porém que dá aos estrangeiros um monopólio temporário sobre os nossos compatriotas, porque os tabacos daqueles se acham na Europa livres da concorrência dos nossos até o mês de abril de cada ano, chegando estes já quando o mercado se acha provido daqueles [...] A retenção forçada dos tabacos nos portos do recôncavo até o dia determinado, fazendo que venham então juntos de uma vez os que aliás poderiam ter vindo sucessivamente à medida, que se fossem aprontando, faz que cheguem também quase ao mesmo tempo, e não é possível descarregarem todos, e recolherem-se na casa da arrecadação (BRITO, 1923: 79/80).

Segundo Brito (1923: 80), essa situação gerava a perda de qualidade do tabaco, pois sendo a casa de arrecadação pequena, não podia receber toda a produção da região, ficando o produto exposto "ao sol, à chuva e às águas do mar, que lhes deterioram a qualidade, vindo por esta maneira a desacreditá-los a mesma providência estabelecida para os acreditar."

E existiam mais restrições: antes de ser comercializado, o tabaco necessitava receber uma aprovação, a qual ficava a cargo de examinadores; sem tal aprovação o 
produto era proibido de embarcar para a Europa. Brito criticou essa condição de comércio e se utilizou dos preceitos de Adam Smith e Jean-Batist Say, alegando que a compra ou a recusa de tabaco sem qualidade ou sem aprovação, deveria ficar a critério do freguês (BRITO, 1923: 71).

Contudo, mais problemas derivavam da determinação da data de embarque do tabaco: sua retenção na casa de arrecadação gerava acúmulo e ocupava um grande espaço, impedindo que outros gêneros dessem entrada; além disso, congestionava também os meios de transporte (então carregados de tabaco à espera de despacho), o que encarecia demasiadamente os fretes e ainda retardava o abastecimento de muitos gêneros, gerando escassez e carestia.

Dessa forma, fica evidente que, no entendimento de Brito, ao invés de abundância, a tutela exercida pelo poder público sobre os produtores, em nome de um pretenso bemestar coletivo, acabava provocando problemas de abastecimento, carestia e pobreza na colônia.

O mesmo tormento vivido pelo lavrador aplicava-se também aos que se atreviam a vender o gado em Salvador para fornecimento de "carne verde". O pecuarista era obrigado a conduzir seu gado por uma "única estrada tralhada por muitos milhares de rezes onde só encontram uma grande parte do ano para comer poeira”. Muitas rezes morriam pelo caminho, e de todas as cabeças que lhe faltavam naquele ermo desde que "passa o primeiro registo (sic), é obrigado a dar justificação perante o Superintendente da Feira, carecendo para isso do favor dos soldados da patrulha, criada para bloquear as boiadas" (BRITO,1923: 65). E da mesma forma como os lavradores eram espoliados pelos Meirinhos nos portos, nos sertões os condutores de gado o eram pelos soldados de patrulha, "criada para bloquear as boiadas", ficando assim, "o Comércio bloqueado por mar e por terra" (BRITO, 1923: 65).

A ironia de Brito é crescente. Sua descrição acompanha a escalada de abusos praticados contra os produtores. Mesmo depois de chegado a Salvador, continuava a via sacra do boi e do boiadeiro:

Quando finalmente o condutor chega à cidade é obrigado a meter nos currais o resto do gado... e nem então se lhe faculta a liberdade de vender a sua carne em o lugar que lhe agrade. ...o pobre homem é obrigado a entregar sua fazenda a uma administração alheia, não lhe restando mais nem o arbítrio de eleger os açougues, onde lhe convém vender a sua carne, nem os Cortadores que hão de 
corta-la, nem mesmo a liberdade de pesa-la nas suas balanças, e cobrar o dinheiro pela sua mão. Ele a vê ir conduzida para um açougue, onde não pode ordinariamente achar um número de compradores proporcionado ao das rezes, que se mataram no curral, e é obrigado a vê-la apodrecer, ou baixa-la ao preço ínfimo, porque só os que obtêm talhos privilegiados, chamados faculdades, podem vender a qualquer hora: os outros são obrigados a esperar pela pauta, que assina esse Senado, para a distribuição dos talhos, e sem esta chegar se não pode pesar as carnes (BRITO, 1923: 65/66).

A passagem acima selecionada é de causar perplexidade. O produtor de gado era obrigado a passar por caminhos determinados, a introduzi-lo nos currais públicos determinados e vender a carne nos açougues públicos determinados! Como não bastasse, não podia escolher os seus "Cortadores" e nem mesmo tinha a liberdade de pesar a carne em suas balanças, fato que mereceu crítica de Brito, pois para ele, "fazer delas monopólio parece exemplo funesto, é praticar o que deve punir nos outros" (BRITO, 1923: 88). E como observamos na transcrição, até o horário em que a carne poderia ser comercializada deveria esperar pelo parecer do Senado.

Em relação ao negócio do gado, Brito fez a defesa dos intermediários entre produtor e consumidor, mas intermediação livre, sem as licenças ou fianças que tinham o efeito de limitar o número de intermediários, gerando situação de monopólio. Pois ao se limitar o número dos marchantes, "direta ou indiretamente, ficaram os criadores de gados na sua dependência; porque chegando à feira, não encontram mais que os poucos compradores" (BRITO, 1923: 77).

Ainda sobre os monopólios na negociação do gado, o desembargador apontou para os prejuízos que eles causavam, afirmando que

os poucos que alcançam a fortuna de poder comprar, e vender, logram de fato o monopólio deste importante ramo da subsistência do povo, em dano grave tanto dos criadores, que são então obrigados a vender-lhes os gados por menos do seu valor por falta de concorrência de compradores, como dos consumidores da Cidade, que hão de forçosamente comprar a carne mais cara, pela falta de concorrência e vendedores (BRITO, 1923: 77).

Vale ressaltar que Brito considerava os atravessadores benéficos tanto para quem vendia quanto para quem comprava; sua restrição em relação a eles se dava em função ao seu número reduzido. As poucas licenças concedidas para se atuar naquele ramo 
conferiam aos negociantes uma espécie de monopólio na intermediação entre o produtor e o consumidor; esses poucos privilegiados poderiam formar um cartel para controlar o preço nas duas pontas do negócio, na compra e na venda. Assim, o credenciamento de poucos atravessadores, ao contrário do pretendido, era prejudicial tanto ao produtor quanto ao consumidor, vale dizer, prejudicial ao conjunto da sociedade. O sensato, segundo o autor, seria a atuação de muitos deles para que houvesse concorrência, o que socorreria o lavrador e o comprador, pois a "própria concorrência de uns impede os outros de se locupletarem com ganhos exorbitantes, que só o não são quando qualquer outro Cidadão pode concorrer a participar deles, fazendo livremente o mesmo giro" (BRITO, 1923: 77).

Todavia, Brito ainda apontaria para outro segmento no qual a intervenção estatal ao invés de agir em favor do bem público acabava por prejudicá-lo: o sistema de crédito. Segundo o autor, também a tutela exercida pelo poder público sobre o crédito para financiar a produção e a circulação da riqueza era prejudicial à prosperidade. $\mathrm{O}$ crédito era escasso e caro porque o Estado tentara não só fixar a taxa de juros, mas também se metera a proteger o devedor contra o credor. Herança, segundo ele, dos "séculos da ignorância e superstição" em que se pensava que não era lícito pagar juro pelo uso do dinheiro alheio tomado de empréstimo. O resultado dessa intervenção foi desastroso porque o favorecimento de uma das partes impediu "a introdução dos capitais estrangeiros" e fez com que os "capitalistas" nacionais achassem para seus capitais “emprego mais lucrativo que o juro da lei” (BRITO, 1924: 104).

Além dessa questão, outro problema oriundo da proteção concedida pela lei ao devedor seria o estímulo ao calote. De acordo com Rodrigues de Brito, adotara-se "o expediente de conceder aos lavradores o privilégio de não poderem rematar-se as fábricas de seus engenhos por execução dos credores", falso remédio que "só veio agravar o mal, porque lhe aumentou as causas, que consistiam na dificuldade de obterem capitais, e na facilidade de dissiparem em superfluidades os que possuíam" (1923: 106). Assim, o meio circulante necessário para financiar a lavoura escasseou mais ainda porque "muitos [capitalistas] fugiram de contratar com uma classe de homens, que a Lei privilegiou com a faculdade de serem caloteiros impunemente" (1923: 107).

Mas também o funcionamento da Justiça era responsável pela escassez de crédito. O credor tinha dificuldade em reaver seus bens em caso de inadimplência porque a justiça era morosa e cara. O nó da questão estaria no código de processo e no "sistema emolumentário", o qual fazia com que 
[...] todos os empregados na administração da justiça tenham interesses em multiplicar, complicar, e prolongar os processos; porque quanto mais estes se multiplicam, complicam, e prolongam, mais crescem assinaturas para os julgadores, alegações para os advogados, escritas para os escrivães, e salários para os solicitadores: sendo assim interessados em desunir, e enredar os cidadãos --- Deus desavenha quem nos mantenha --- Eis aqui a oração matutina que lhes inspira o tal sistema emolumentário (BRITO, 1923: 116/117).

Para atalhar esse mal, Rodrigues de Brito propôs uma mudança no código de processo e uma reforma completa nos cursos jurídicos das universidades para que estas adotassem um sistema de instrução pública "nivelada pelas luzes do século", abandonando, assim, o estudo dos Códigos romano e canônico, "tão incompreensíveis, contraditórios e alheios da filosofia dos tempos presentes" (1923: 120).

O desembargador Brito (1923: 118) também refletiu acerca de como deveriam ser encaminhados os processos e ordenados forenses, e sugeriu que ao invés de o Estado taxar salários, aluguéis, preços e juros, taxasse o tempo dos pleitos, "com prazos suficientes para a sua terminação".

Também era extremamente importante que as decisões fossem justas. Inundado pelo espírito das "luzes", ele tocou em grandes questões presentes nos iluministas, como o direito de propriedade e a necessidade de cumprimento dos contratos, ambas consideradas fundamentais para a manutenção da sociedade civil:

Mas não basta que os processos sejam breves, cumpre também que as decisões sejam justas; porque sem isto não se obtém uma perfeita segurança dos direitos de propriedade, e do cumprimento dos contratos, que é o primeiro objeto da sociedade civil, e o mais interessante dos auxílios, com que um Governo pode facilitar aos Lavradores o exercício da sua indústria, e a livre circulação dos capitais (BRITO, 1923: 118).

Nesse sentido, na concepção de Rodrigues de Brito a intervenção do Estado sobre a produção e a comercialização, apenas deveria se dar quando estritamente necessária, acreditando ser "nocivas outras formalidades que possa haver, se não forem precisamente indispensáveis para assegurar a exatidão das qualificações”. (1923: 142) 
Adepto do princípio livre-cambista do "deixai fazer, deixar passar, deixai vender", colocou-nos que "uma administração sábia deixará sempre as mercadorias, e mesmo os gêneros da primeira necessidade à liberdade do Comércio, à concorrência, que não conheça obstáculos", pois "não é do ofício do homem público o intrometer-se no Comércio; deve ser espectador tranquilo" (1923: 144). Assim, era um adepto convicto dos pressupostos smithianos, pois acreditava que "governa melhor aquele que menos governa" (1923: 131).

\section{Considerações finais}

Diante do exposto, torna-se inquestionável a filiação de personalidades como Ferreira da Câmara e Rodrigues de Brito ao grupo reformista liderado por D. Rodrigo. As ideias por eles defendidas no inquérito econômico - que, como mencionamos, por si só expressa o espírito de renovação e o novo modelo que a elite intelectual e administrativa propunha - não se enquadram no velho modelo político-administrativo. Pelo contrário, indicam sua proximidade com as novas concepções.

Nesse sentido, Rodrigues de Brito e os demais pensadores citados neste artigo, ocuparam lugar de grande destaque no cenário político e intelectual do mundo lusobrasileiro, pois o combate ao evidente engessamento ao qual as relações econômicas ainda estavam sujeitas naquele início do XIX, abriu espaço para que inúmeros outros pensadores/personagens manifestassem sua adesão às "novas ideias", criando um importante núcleo de "administradores e intelectuais dinâmicos" (para usar novamente a expressão de Schwartz), responsável pela propagação de conceitos que serviriam de base à agitação política daquele período.

A existência de um grupo intelectual com essas características denota a articulação entre agentes coloniais e metropolitanos, e evidencia a existência, aqui no Brasil, de um grupo de pensadores formados já a partir do novo paradigma inaugurado em fins do século XVIII, baseado na ideia de liberdade, seja no campo social, econômico ou político.

Seriam justamente os homens orientados por essa grande força - as novas ideias que promoveriam, apenas uma década depois do inquérito de 1807, o movimento de independência da Bahia e do Brasil, e sustentariam o novo Império fundado em 1822. 


\section{Fontes}

ALVARÁ DE ABOLIÇÃO DO CONTRATO DO ESTANQUE DO SAL E DA PESCARIA DAS BALEIAS NO BRASIL (24/04/1801). In: COUTINHO, Rodrigo de Souza (Conde de Linhares). Textos Políticos, Econômicos e Financeiros (17831811). Vol. I e II. Introdução de Andrée Masuy Diniz Silva. Lisboa: Banco de Portugal, 1993.

AVISOS E INSTRUÇÕES PARA D. FERNANDO JOSÉ DE PORTUGAL, GOVERNADOR E CAPITÃO GENERAL DA CAPITANIA DA BAHIA. In: COUTINHO, Rodrigo de Souza (Conde de Linhares). Textos Políticos, Econômicos e Financeiros (1783-1811). Vol. I e II. Introdução de Andrée Masuy Diniz Silva. Lisboa: Banco de Portugal, 1993.

BRITO, João Rodrigues de (1923). A Economia Brasileira no Alvorecer do Século XIX. Salvador: Livraria Progresso Editora.

COUTINHO, Rodrigo de Souza (Conde de Linhares). Textos Políticos, Econômicos e Financeiros (1783-1811). Vol. I e II. Introdução de Andrée Masuy Diniz Silva. Lisboa: Banco de Portugal, 1993.

\section{Referências Bibliográficas}

CARDOSO, José Luís \& CUNHA, Alexandre (2011). Discurso Econômico e Política Colonial no Império Luso-Brasileiro (1750-1808). Revista Tempo. vol. 17, n. 31, pp. 65-88.

ELLIS, Myrian (1955). O Monopólio do Sal no Estado do Brasil (1631-1801). Contribuição ao estudo do monopólio comercial português no Brasil durante o período colonial. São Paulo: Universidade de São Paulo.

JANCSÓN, Instiván; PIMENTA, João Paulo G. Peças de um Mosaico (ou apontamentos para o estudo da emergência da identidade nacional brasileira). In: MOTA, Carlos Guilherme (org.). Viagem Incompleta. A experiência brasileira (1500-2000). São Paulo: Editora SENAC São Paulo, 2000.

MAXWELL, Kenneth (2001). A Devassa da Devassa. São Paulo: Paz e Terra.

MENDONÇA, Marcos Carneiro (1958). O Intendente Câmara. São Paulo: Companhia Editora Nacional.

NOVAIS, Fernando A. (1989). Portugal e Brasil na Crise do Antigo Sistema Colonial (1777-1808). 5 ed. São Paulo: Hucitec.

NOVAIS; Fernando A. \& ARRUDA, José Jobson A. (2003). Prometeus e Atlantes na Forja da Nação. Economia e Sociedade. Campinas, v. 12, n. 2 (21), pp. 225-243, jul./dez.

PEREIRA, LUPERCIO A.; PEREIRA, JOSÉ F. \& SILVA, KARLA M. (2009). A Crise do Sistema Colonial No Brasil Vista Sob Uma Nova Perspectiva: uma análise da Carta Econômico-Política de João Rodrigues de Brito (1807). In: PRIORI, Ângelo; PEREIRA, Lupercio A. (Org.). Dilemas do Desenvolvimento Brasileiro. Curitiba: Instituto Memória.

SCHWARTZ, Stuart B. (1999). Segredos internos: engenhos e escravos na sociedade colonial (1550-1835). São Paulo: Companhia das Letras.

SILVA, Andrée Mansuy Diniz Silva (1993). Introdução. In: COUTINHO, D. Rodrigo de Souza. Textos Políticos, Filosóficos e Financeiros (1783-1811). Vol. I e II. Introdução de Andrée Masuy Diniz Silva. Lisboa: Banco de Portugal. 
SILVA, Karla Maria da (2007). A Crise da Economia Colonial: as dimensões internas das práticas mercantilistas nos escritos de Brito e de Vilhena. Dissertação (Mestrado em História). Universidade Estadual Júlio de Mesquita Filho, Assis, SP.

SMITH, Adam (1996). A Riqueza das Nações. Coleção Os Economistas. Vol. I e II. São Paulo: Nova Cultural, 1996.

Artigo recebido em 30 de agosto de 2016.

Aprovado em 20 de novembro de 2016.

DOI: $10.12957 /$ intellectus.2016.26662 